\title{
Sierra Leone: Poverty Reduction Strategy Paper Preparation Status Report
}

Poverty Reduction Strategy Papers (PRSPs) are prepared by member countries in broad consultation with stakeholders and development partners, including the staffs of the World Bank and the IMF. Updated every three years with annual progress reports, they describe the country's macroeconomic, structural, and social policies in support of growth and poverty reduction, as well as associated external financing needs and major sources of financing. This country document for Sierra Leone, dated September 15, 2004 is being made available on the IMF website by agreement with the member country as a service to users of the IMF website.

To assist the IMF in evaluating the publication policy, reader comments are invited and may be sent by e-mail to publicationpolicy@imf.org.

Copies of this report are available to the public from

International Monetary Fund • Publication Services

$70019^{\text {th }}$ Street, N.W. • Washington, D.C. 20431

Telephone: (202) 623-7430 • Telefax: (202) 623-7201

E-mail: publications@imf.org • Internet: http://www.imf.org

Price: $\$ 15.00$ a copy

\section{International Monetary Fund Washington, D.C.}





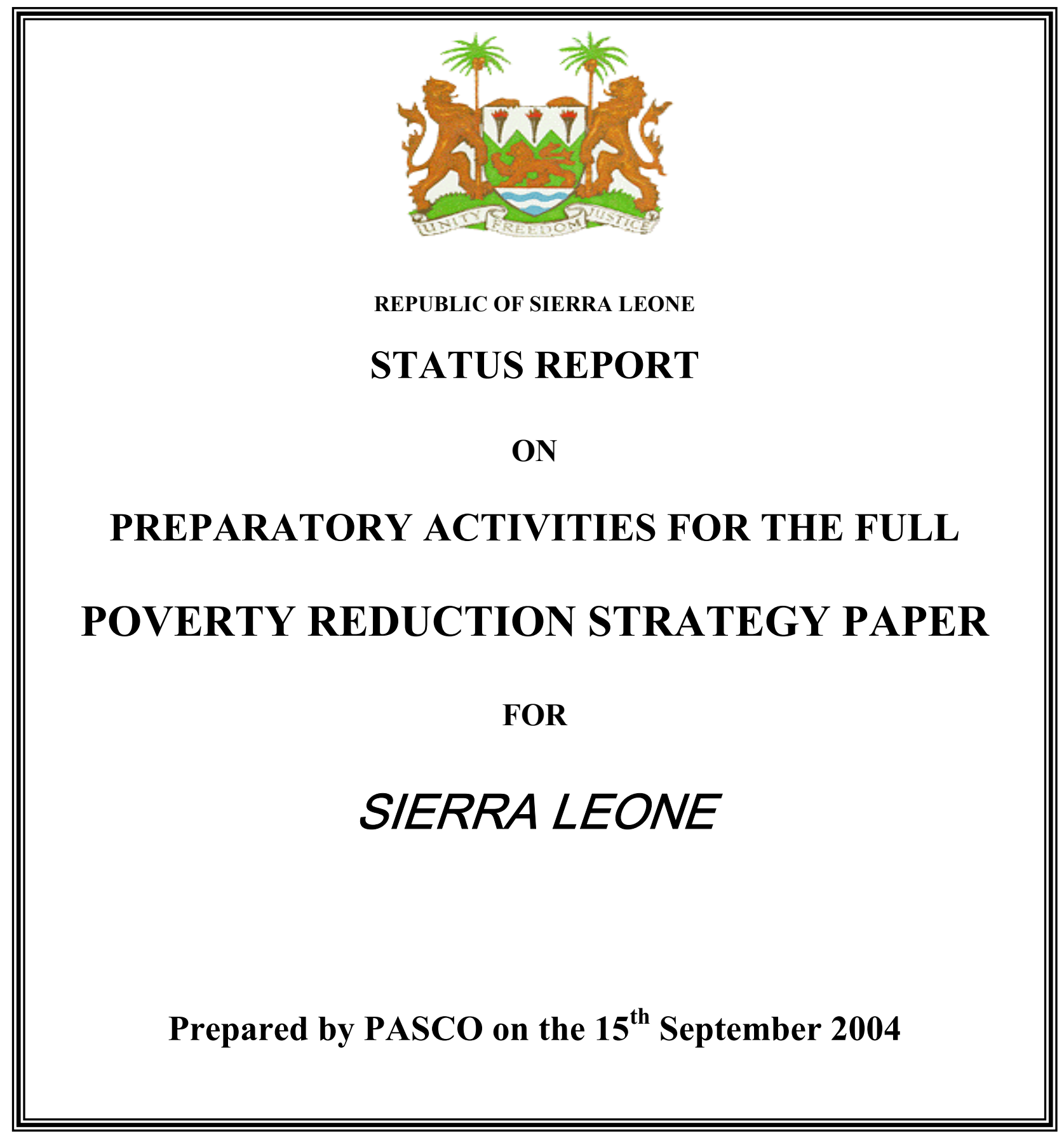




\section{Sierra Leone Poverty Reduction Strategy Paper - Preparation Status Report}

\section{A. INTRODUCTION}

1. The Government submitted its last PRSP preparation status report to the Executive Boards of the IMF and the World Bank in June 2003. However projected completion date of December 2003 has been missed due to continuing administrative and technical difficulties as well as delays in accessing technical and financial assistance from key partners. To fast track the process, the Government appointed a Technical Working Group within PASCO under the direct supervision of the Vice President and provided substantial resources to complete the various processes

2. As a result of this arrangement, a draft PRSP has been prepared and issued in August 2004 to all stakeholders for comments and suggestions. The draft however excludes the cost of activities for public policies and programmes. Comments are expected from all partners and stakeholders between September and October 2004 and a final PRSP will be issued by December 2004

3. This status report outlines the various stages and processes leading to the production of the draft PRSP. Implementation arrangements for an effective monitoring and evaluation system are also discussed.

\section{B. Participation and Consultative Processes}

4 The specific objectives of the PRSP consultative process were to: a) inform the population of the process, their role in its formulation and consequently enhance their participation b) generate information on the dimensions, coping mechanisms, and trends in poverty; and c) assess the impact of government policies on the poor

5 Two processes characterised the participatory and consultative aspects in the formulation of Sierra Leone's PRSP. First, the main government processes coordinated by the Poverty Alleviation Strategy Coordinating Office (PASCO) and second, a 'Civic Engagement Process' coordinated by NGOs and civil society. The main Government processes included the following: Participatory Poverty Assessments (PPAs), Strategic Planning and Action Process / Focus Group Discussions (SPP/FGDs) and Risk and Vulnerability Assessment (RVA), a number of consultative workshops on specific themes and national and district consultations and validation workshops.

6 The primary objective of the PPAs was to ensure that the voices, perspectives and priority needs of poor people are reflected in government policy; and to provide information on people's perceptions of the definitions, causes, categories, impact and characteristics of poverty. PPAs were conducted in 42 communities in all the districts in March 2003. Additional assessments were done in 14 communities in March 2004. The exercises covered four communities per district, including the Western Urban and Rural areas with an average participation of 130 participants per location. Key findings from 
the PPAs are that people see poverty as the lack of basic needs and services. The most common manifestations of poverty were lack of food, money, shelter, clothing and basic services such as health, school and safe drinking water. Hunger was of primary concern to children.

7. The aim of the SPP/FGDs was to identify development priorities and strategies through a highly participatory citizen's consultative exercise to define a National Strategic Vision (NSV). The exercise was conducted with cabinet ministers, parliamentarians, government officials and specialized groups such as mass media, women, Internally Displaced Persons, ex-combatants, children, youths, local authorities, religious leaders and civil society organisations during September-October 2003. A second round of focus group discussions were conducted during March-April 2004 in all district headquarter towns, and the two districts in the Western Area. Participation in each district comprised representatives from all of the 149 chiefdoms and the 5 wards in the Western area covering a broad spectrum of society. A total of about 1,260 representatives nation-wide participated in the FGDs. The five top national priorities that emerged from the focus group discussions were Education - 25 percent, Agriculture - 20 percent, Health - 17 percent, Good Governance - 14 percent and Infrastructure - 4 percent. Other high scoring priorities were Security, Labour and Employment, Energy and Power.

8. A series of validation and consultative meetings and workshops were conducted at national, district, chiefdom and community levels during the sector reviews and on specific themes such as HIV/AIDS, gender and children.

9. The 'Civic Engagement Process' of the PRSP independently led by civil society provided a comprehensive national framework that synchronised the different programmes for civic engagement on the PRSP process. The exercise is coordinated by Action Aid Sierra Leone (AASL), supported by a team of four CSOs (known as Regional Implementing Partners) assigned with the responsibility of coordinating the civic engagement process in the four regions. The partners are: Network Movement for Justice and Development (NMJD), responsible for the Southern Region; Council of Churches Sierra Leone (CCSL), responsible for the Northern Region; Movement for the Restoration of Democracy - Sierra Leone (MRD- SL), responsible for the Eastern Region; and Urban Development Area (UDA- AASL)/FAWE, responsible for the Western Area. Its purpose was: a) promote learning, shares and debate on the PRSP; b) provoke response and feedback into the PRSP process, and c) Monitor the process of formulation, implementation and recommend corrective actions. The process targeted all levels of society irrespective of sex, generational and ethnic differences throughout the country. In all, 699 men, 599 women and 268 children were consulted. About 757 men and 354 women participated in Participatory Learning Forum (PLF) workshops.

\section{Poverty Analysis}

10 A number of quantitative and qualitative sources of data have been used for a comprehensive diagnosis and a better understanding of poverty. The major quantitative data was generated from the Sierra Leone Integrated Household Survey (SLIHS) carried 
out by Statistics Sierra Leone (SSL) over a twelve-month period-May 2003 to May 2004. The information provided by the survey indicates that poverty is pervasive and deep seated in Sierra Leone.

11. Using the National Poverty Line of Le2,111 per day, the national Poverty Head Count $\left(\mathrm{P}_{\mathrm{o}}\right)$ estimates that about 70 percent of the population of Sierra Leone are poor. Also, about 68 percent of the population cannot even afford enough food and 26 percent are in extreme poverty. The poor in Sierra Leone can meet only about 71 percent of their basic needs.

12 Poverty is heavily concentrated in the rural and other urban areas outside Freetown. One salient characteristic of poverty in Sierra Leone is that, at 75 percent, the incidence of food poverty in provincial cities is higher than the national average of 68 percent. In Freetown, 38 percent of the population cannot afford enough food compared to 75 percent in the provincial cities.

13 The full poverty line indicates that the incidence of poverty is lower in the provincial cities at 70 percent compared to the rural areas at 79 percent. Only 15 percent of the population in Freetown falls below the full poverty line. The rural areas contribute almost about 73 percent to total incidence of poverty. With the exception of Western Area, more than 55 percent of the population in all districts live in poverty. Kailahun has the highest incidence of poverty, as it is the worst off district with 92 percent of the population living below the full poverty line.

14. Qualitative information on poverty was also obtained from the poor themselves through a combination of the Participatory Poverty Assessments (PPAs), the Strategic Planning Process/Focus Group Discussions (SPP/FGDs) and the civic engagement process pioneered by NGOs and civil society organisations. According to the assessments, the poor view poverty as lacking basic needs and services, which include food, money, shelter, clothing, health facilities, schools and safe drinking water. The most frequently perceived qualitative causes of poverty by the poor are laziness (where laziness is defined as a negative attitude to work), followed by ill health, the civil conflict, disunity, victim of theft, and lack of education. Poverty is manifested in various forms including hunger and malnutrition; being in a constant state of worry (vulnerability); increase in school dropouts; loss of respect, dignity and integrity; maginalisation and isolation; migration and separation of families; and tension and increased violence in the home and in the community.

\section{Sector Reviews and Public Policy Priorities}

15 Five sector/thematic working groups (established for the formulation of the PRSP) were: i) Macro-economic Policy and Private Sector Development, ii) Social Sector Development, iii) Reconstruction, Rehabilitation and Reintegration iv) Agriculture Natural Resources and the Environment and v) Governance and Security. Sector working sub-groups covered five Cross Cutting Issues-Gender, Youths, HIV/AIDS, Children, the Disabled and the Environment. The working groups collaborated with both local and 
international consultants and reviewed existing policies and programmes identified gaps, defined new policies, and developed monitorable targets and indicators through workshops and consultations with the poor rural communities, staff in sector ministries and relevant players in each sector.

16 The broad policy objectives of Government and national priorities that emerged through consultations include: i) Support to agriculture and ensure food security; ii) Raise productivity and promote employment opportunities and income generating activities; iii) Improve access to basic social services especially health, water and sanitation and education; iv) Rehabilitate infrastructure and support private sector development and micro finance activities and v) Promote good governance and ensure a secured and peaceful environment

\section{E. Implementation and Capacity Building}

17 The implementation of the PRSP will be the responsibility of all Sierra Leoneans. The general framework will consist of the central Government, the newly created District, City and Town Councils, NGOs, civil society, community based organisations and the private sector. Effective collaboration and coordination among these entities will be crucial to the achievement the overarching goals of food security, job creation and poverty reduction.

18 The central Government will play the leading role and have overall responsibility for implementation of the PRSP. The line ministries, National Commissions, etc already have statutory responsibilities for formulating policies, designing programmes, and supervising all public sector interventions addressing the needs of the population. Each of these central bodies have provincial and district level units/branches responsible for implementation, supervision and/or monitoring programmes at those levels. However, with the decentralisation of governance and the establishment of 19 representative local government structures across the country, the traditional role of central government will change. Although sector policy decisions and budgeting will be retained at the centre, all other functions will be devolved over time.

19 NGOs, civil societies and community-based organisations will continue to have a critical role to play in implementation. However, for the PRSP, an inclusive co-ordination mechanism is envisaged, particularly at District level, in order to maximise the benefits of pro-poor programmes to the beneficiary population.

20 A large number of institutions will be involved in the implementation of the programmes in the PRSP at all levels - national, district, chiefdom and ward. Coordination and implementation arrangements will therefore be structured in a flexible manner to accommodate the diverse entities in Government, civil society, local communities and the Private Sector. 
21 The overall coordination of implementation of the PRSP will be vested in a Poverty Reduction and Development Assistance Coordination Office (PRDACO) with the full participation and collaboration of all MDAs, CSOs and international development partners. This reflects the diverse and difficult institutional environment that has characterised the preparation of the PRSP and the need to fast track operationalisation of the strategy. PRDACO will be situated in the Office of the Vice President and work closely with MoDEP and MoF.

22 PRDACO will be the focal point or Secretariat for PRSP coordination, monitoring and evaluation on the one hand and coordination of development assistance from multilateral agencies, bilateral partners and NGOs on the other. A Poverty Reduction and Analysis Unit will be set up within the office to coordinate planning, implementation, monitoring and evaluation of the PRSP and work closely with some of the preparatory structures established by government and the NGOs. Specific Terms of Reference will be prepared to clarify roles and responsibilities and institutional relationships with existing MDAs. The present DACO will be amalgamated into the PRDACO as a Unit providing the secretariat for DEPAC and monitoring flows through the government budget and projects and the NGOs.

\section{PRSP Implementation Linkages with the MTEF}

23 PRSP implementation will aim at improving current expenditure planning, management and tracking systems with a view to maximising impact of the government's development programme. A MTEF has already been established by government in collaboration with the donor community (and civil society). From 2005, the MTEF will be aligned to the PRSP and a Medium-Term Resource envelop consisting of both government and external resources.

24 The annual budget will be the primary instrument for effecting expenditures for PRSP priorities in the next three years. Within the period, MoDEP and MOF will synchronise the PRSP, MTEF and PIP (the mid term capital budget or development budget) to ensure greater efficiency and effectiveness in implementing governments Poverty Reduction Strategy.

\section{Capacity Building}

25 The number and quality of institutions, systems of service delivery and human resources are recognised as some of the key obstacles to any forward march. Capacity for programme design, implementation, economic and financial management in the public and non-public sectors has declined progressively over the last two decades.

26 Government's efforts have focused largely on gap filling with contract workers being engaged to fill strategic staff positions in the civil service. As the country transitions from a relief and recovery phase to a development phase with the implementation of a comprehensive PRSP, it has become imperative for capacity building to be brought into sharper focus with a longer-term perspective. It has already 
been recognised that a weak public sector cannot deliver the goods and services for sustainable growth and poverty reduction. Also, a major shift and re-orientation is required from technical assistance to the building of indigenous human and institutional capacity to meet the development challenges facing the country.

27 Implementing a capacity building programme on the scale required to translate the PRSP into an achievable goal will require substantial support from Sierra Leone's development partners over the short to medium-term. The programme will seek to do the following: a) Identify the administrative, technical and logistical needs of Government Ministries, Departments and Agencies, Civil Society and NGOs involved in the implementation of the PRSP; b) Determine training needs, relevant training programmes and sources of sponsorship for staff training and c) Provide the necessary administrative, technical and logistical support for implementing institutions and agencies, and d) Establish an effective management information system for the PRSP.

\section{F Monitoring and Evaluation}

28 A new monitoring and evaluation system will guide the design, implementation and analysis of the full poverty reduction strategy and the changes that might occur as a consequence of the interventions. Monitoring and evaluation will be an essential management tool both in the pursuit of policy, programme and project effectiveness and to ensure accountability, responsiveness and transparency in the allocation of resources.

29 The institutional framework supporting the M\&E system will involve many agencies both within the public sector (line ministries, commissions, local councils, etc) and without (NGOs, CBOs, CSOs). This reflects the broad interest generated and the participatory approach to preparation of the PRSP and the transparency in governance espoused by government. Unlike the situation for the IPRSP, the M\&E framework will involve greater coordination of efforts of all the institutions.

30 A Poverty Reduction Analysis Unit (PRAU) will be established as part of PRDACO. This unit will take the lead responsibility for coordination of all PRS monitoring activities. It will employ a senior monitoring and evaluation specialist and a technical support staff that will include a data coordinator, database manager and GIS expert. In particular it will:

- Develop a detailed annual work plan, which will identify those responsible for attaining agreed monitoring activity benchmarks;

- Prepare quarterly reports on activities and progress towards the attainment of specified indicators or bench marks;

- Compile the core PRS monitoring indicators;

- Prepare detailed annual PRS monitoring reports;

- Oversee and coordinate the activities of four specialised PRS monitoring working groups which will comprise relevant staff from government and non-government agencies to collaborate on the following areas: 
i) Resource allocation and expenditure

ii) Censuses/surveys and routine data systems

iii) Community based monitoring

iv) Dissemination, research and policy analysis.

31 The Economic Policy Research Unit of the Ministry of Finance established the PETS Task Team in 2001. Its objective was to design a survey which could track the flow of public resources from the point of budget allocation to their end use, for example, in frontline service delivery facilities. The PETS survey, which focused on three specific resource flows which took place over the 2002 financial year: school fee subsidies; teaching and learning materials; and essential drugs has been produced and circulated. The survey covered more than 600 schools and 130 health facilities. The PETS will therefore be continued on an annual basis during the PRS period and are regarded as a central component of the monitoring system, especially in terms of their ability to address a range of issues relating to accountability, transparency and efficiency under the Good Governance Pillar of the PRSP.

32 The compilation of data by ministry representatives sitting on the District Recovery Committees (DRCs) and supported by OCHA has provided a valuable source of information on the major social sectors over the recovery period. This data has been entered into the National Recovery Database (NRD) by SLIS and used to prepare both district and sector 'Data Packs', which can be used to estimate a number of core PRS indicators. This system will continue at least into the initial years of PRS implementation, though with the OCHA role being played by the newly created Transition Support Teams (TST). Over time, as the decentralisation process is implemented, the intention will be that the development planning committees of the new local councils take over the monitoring role of the DRCs and TSTs.

33 Over recent years, considerable insight has been gained on the extent, depth, nature and causes of poverty from a series of national household surveys. The findings of these surveys have been fed into the PRSP process and will provide baseline data that will be used in the estimation of many of the PRS monitoring indicators. They include:

- $\quad$ Multiple Indicators Cluster Survey (MICS), UNICEF, April 2000.

- $\quad$ School Census, KPMG, 2002.

- $\quad$ Governance and Corruption Survey, Conflict Management and Development Associates (CMDA), 2002.

- Vulnerability Survey, World Food Programme, March 2003.

- Integrated Household Survey, Statistics Sierra Leone, April 2003 - March 2004.

34 A number of additional surveys and a household census are at the advanced planning stage and will be implemented later this year or early next. These include:

- Census, Statistics Sierra Leone, December 2004

- Vulnerability Survey, World Food Programme, October 2004. 
- Core Welfare Indicators Questionnaire Survey (CWIQ), SSL, April 2005

- $\mathrm{MICS}, \mathrm{UNICEF}, 2005$

35 The Vulnerability and CWIQ Surveys, are intended to be undertaken annually through the PRS period and will provide a valuable source of monitoring data. The CWIQ has been specifically designed to allow routine annual monitoring of poverty reduction initiatives. The Vulnerability Survey, will be of particular use as a source of PRS information in the priority areas of food security and malnutrition.

36 The PPAs have been established as a key tool in Sierra Leone for poverty monitoring. They were used to inform the PRSP process, and are institutionalised in government sectors, most notably in PASCO and NaCSA. PPAs can be adapted to elicit information on almost any number of issues at the grassroots level. They will be useful in determining people's perceptions of government service delivery in a broad manner, which may include attitudes to government service providers and assessments of their capacity.

37 The SPP methodology and Focus Group Discussions, applied to engage citizens in the preparation of the PRSP, have proved an excellent source of information. These exercises will be used during the implementation phase to monitor government service delivery at grassroots level, and will also be adapted to facilitate participatory monitoring and evaluation of PRS projects and programmes. The information gathered will assist in establishing people's perceptions of the progress being made in the priority service delivery areas and necessary improvements.

38 Tracking and monitoring progress in implementation of the PRS will rely on an appropriate mix of intermediate (input/output) and final (outcome/impact) indicators. While the former are generally under the control of the implementing agencies, the latter are usually not. As indicated above, a range of methods will be used to track both types of indicator. In general the MDAs will be expected to provide information on intermediate indicators to measure progress in their respective sectors and other sources, for example, household surveys, will be used to estimate final indicators.

39 A number of sectoral indicators have already been selected through intensive consultative processes involving full participation of all sector representatives. Indicators selected during the IPRSP were also revisited and re-examined for their relevance to measuring progress. The medium-term indicators of the PRSP will also be aligned with the longer-term MDGs (of 2015) by the end of 2004.

40 Over the first year of PRS implementation, while monitoring systems are being developed and capacity built, the PRAU will focus on a 'core' sub-set of indicators which can be reliably estimated using tested sources and methods. These have been selected on the basis that they can provide relative rapid feedback on progress that can be directly attributed to PRS projects and programmes. 


\section{G DONOR RESPONSE TO FIRST DRAFT PRSP}

41 Following the submission of the draft PRSP to donors at the end of August, PASCO received the first comprehensive reaction at the $9^{\text {th }}$ DEPAC meeting of $16^{\text {th }}$ September 2004. The various reactions could be summarised as follows:

1. The PRSP drafting team was commended for producing an excellent draft document that addresses poverty reduction issues in Sierra Leone.

2. There was general consensus that a lot of work has gone into getting the first draft out and the wide level of consultation and participation of all stakeholders was highly commendable.

3. The document was said to be highly comprehensive with lots of proposed strategies and actions that have been given equal weight without prioritising. Prioritised programmes should include short and long term choices with out crowding out vital area. Areas that can have immediate impact on poverty reduction should be included in the short-term strategies whilst making provision for those areas that promote sustainable development in the long term.

4. The issues of food security, youth unemployment and good governance were clearly identified as key priority themes for a successful poverty reduction strategy. The issues of hunger, food security and nutrition were not fully addressed in the document through they emerged as critical issues. They were subsumed under the agriculture chapter. A chapter that addresses food security should be developed. The nutrition component under health should be strengthened.

5. Because majority of the poor live in rural areas, the PRSP should focus on making the rural poor more productive in the agricultural sector by a) Improving accessibility to money b) Accessibility to loans with strong mechanism that will ensure repayment c) Establishing agricultural banks.

6. The PRSP should also address the issues of the urban poor particularly the youths.

7. It was agreed that there is need to repackage the information in the document, outlining clearly the linkages between the pillars, the sectors, objectives, the implementation strategies and benchmarks.

8. Efforts should be strengthened in the productive sectors i.e. mineral and marine resources for domestic revenue generation to complement external assistance to finance poverty reduction programmes.

9. The PRSP addresses gender and children issues and well as the MDGs. 
10. Clarification should be made between the child first and vulnerable issues. Budgetary allocations and macro economic policies should be child friendly for the next three years. Also to reinstate the policy of the family as the first place of care for the child.

11. The Security sector should include a risk analysis component. Cross-border security to be emphasised, particularly trafficking in small arms. Also, to identify risk analysis in the security sector.

12. Programmes and activities should be clearly prioritised before costing. The costing exercise should be embedded within the government's budgetary process i.e. the MTEF. Government should also indicate how it intends to raise and utilise its resources on prioritised programmes.

13. The effort of government in addressing corruption issues has to be reflected in the PRSP to allay donor concerns for the efficient management of resources.

14. Capacity building and strengthening elements should be identified for key implementing institutions and these include a) Human resource development and technical assistance b) Computer technology and data bases c) Supporting implementing partners such as local government and civil society. Capacity building should focus on partnership and civil society should be strengthened to ensure accountability and transparency during implementation.

15. The importance of the implementation of the PRSP was stressed and this needs to be carefully reviewed in the light of current capacities within central and local government as well as among civil society organisations. Some therefore recommended that the implementation process be anchored in existing institutions to avoid creating parallel institutions performing the same functions. The roles of MOF and MODEP need to be clarified in the implementation arrangements because of their strategic functions in financing and budgeting, and coordinating the development programmes respectively. However, it was recognised that some government institutions are weak and may not be able to effectively carry out the implementation exercise. Capacity building for these institutions was highly recommended.

16. The PRSP marks an important point for post-conflict transition to development in Sierra Leone; therefore is need to have a timetable for the Consultative Group (CG) meeting with donors.

17. A smaller team should be constituted to work on the final draft. The team should collaborate with some in-country donor representatives and civil society groups to now identify key priority programmes and activities that would provide the basis for costing of the PRSP. 


\section{E NEXT STEPS IN COMPLETION OF FINAL DRAFT PRSP}

42 The following steps are envisaged to finalise the document.

\begin{tabular}{|l|l|l|l|}
\hline NO. & ACTIVITY & TIMEFRAME & REMARKS \\
\hline 1. & $\begin{array}{l}\text { Incorporation of comments } \\
\text { from all stakeholders }\end{array}$ & $20^{\text {th }}$ Sept $-4^{\text {th }}$ Oct & \\
\hline 2. & Prioritisation of Activities & $15^{\text {th }}$ October & \\
\hline 3. & Finalisation of Indicators & End October & \\
\hline 4. & $\begin{array}{l}\text { Costing of Priority } \\
\text { Activities/Programmes }\end{array}$ & End November & $\begin{array}{l}\text { Two weeks before } \\
\text { DEPAC }\end{array}$ \\
\hline 5. & Draft II & $4^{\text {th }}$ November & \\
\hline 6. & Final Draft & End November & \\
\hline
\end{tabular}

